\title{
ENVELHECIMENTO NAS ORGANIZAÇÕES: PRECONCEITO OU TENDÊNCIA?
}

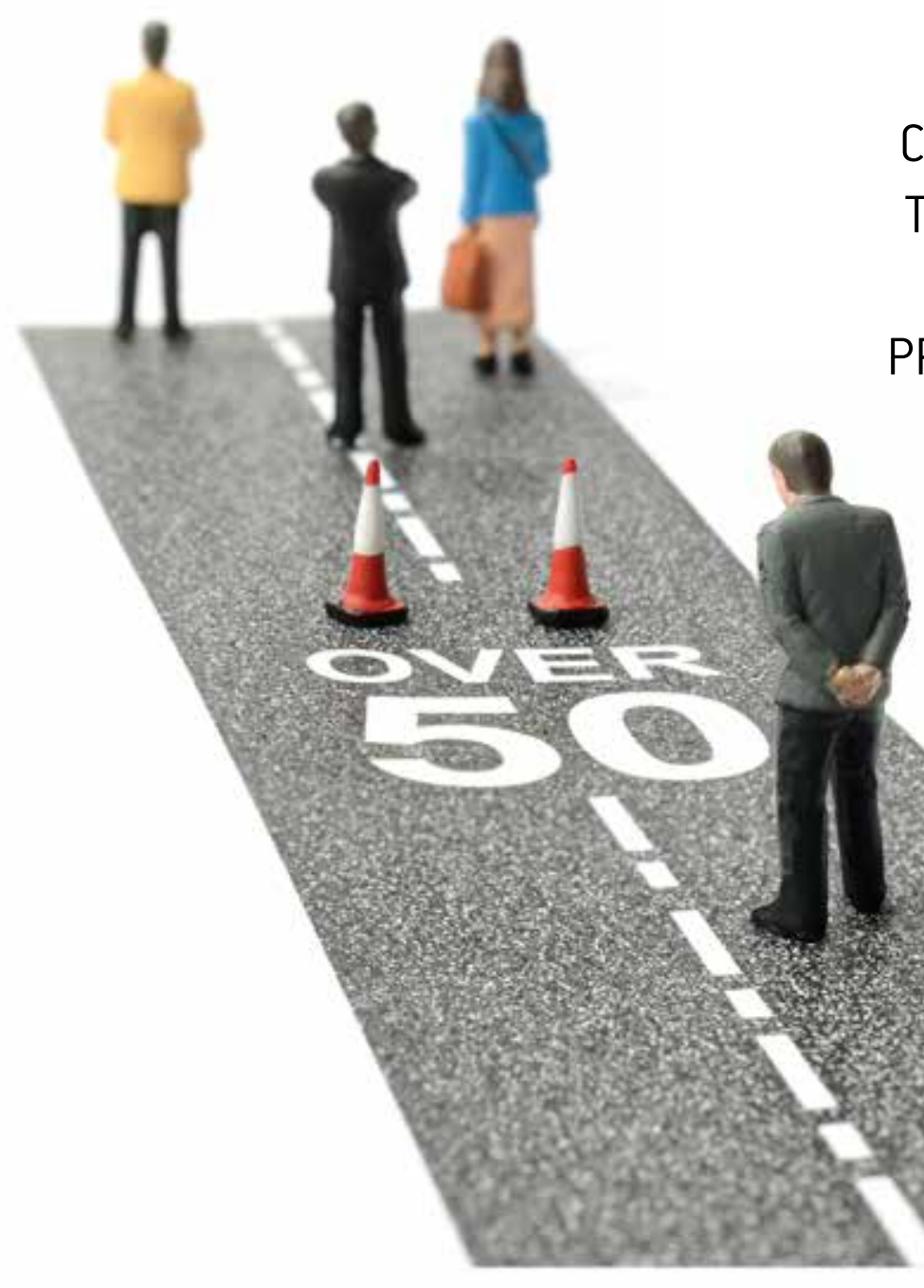

A POPULAÇÃO BRASILEIRA ESTÁ SE TORNANDO MAIS VELHA E, CONSEQUENTEMENTE, A FORÇA DE TRABALHO TAMBÉM. NO ENTANTO, O PRECONCEITO CONTRA ESSES PROFISSIONAIS É CADA VEZ MAIOR. SERÁ QUE AS ORGANIZAÇÕES ESTÃO PREPARADAS PARA LIDAR COM ESSA NOVA REALIDADE?

| POR VANESSA MARTINES CEPELLOS + MARIA JOSÉ TONELLI + FRANCISCO ARANHA + JOÃO LINS PEREIRA FILHO 


\section{COMPROMETIMENTO, FIDELIDADE, PONTUALIDADE, CAPACIDADE DE REALIZAR DIAGNÓSTICOS E EQUILÍBRIO EMOCIONAL SÃO ASPECTOS POSITIVOS ASSOCIADOS AOS PROFISSIONAIS MAIS VELHOS}

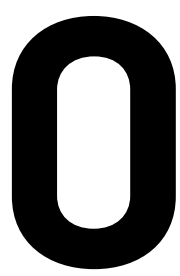

fato de que o Brasil está envelhecendo é inegável. Para se ter uma ideia, de acordo com o relatório Envelhecendo em um Brasil mais velho, divulgado recentemente pelo Banco Mundial (BIRD), em 1950, os idosos com 60 anos ou mais representavam $4,9 \%$ da população total; em 2010 , esse número já havia saltado para $10,2 \%$ e, caso as projeções se confirmem, no ano de 2050 eles irão corresponder a $29,7 \%$ dos brasileiros.

O envelhecimento populacional implica diretamente no envelhecimento da força produtiva. Isso significa que, em um futuro próximo, os empregos serão ocupados por pessoas com mais de 45 anos, fato que exigirá iniciativas de gestão específicas às necessidades desses profissionais.

Não há dúvidas de que o preconceito contra os mais velhos é uma realidade. O ageism é o termo cunhado pelo gerontologista Robert N. Butler, em 1968, para descrever a discriminação etária que ocorre com adultos de idade avançada. Juntamente com o sexismo e o racismo, o ageism tem sido apontado como um problema nas empresas nacionais e internacionais.

Em nosso país, a discussão a respeito do ageism e das práticas de gestão da idade ainda estão no início. Entretanto, não se pode mais esperar para refletir a respeito do envelhecimento do profissional brasileiro devido à velocidade com a qual o país está se tornando mais velho. A França, por exemplo, demorou mais de um século para dobrar a sua população idosa, ao passo que o Brasil terá essa mesma variação demográfica nas próximas duas décadas.

Será que as empresas no Brasil estão preparadas para esse desafio? Como são vistos, hoje em dia, os profissionais mais velhos que atuam nas organizações instaladas aqui?

Com o intuito de responder essas perguntas, a FGV-EAESP, em parceria com a PricewaterhouseCoopers (PwC), realizou uma pesquisa quantitativa com 138 gestores de Recursos Humanos de empresas atuantes no país e chegou a conclusões intrigantes sobre a problemática.

\section{PERCEPÇÕES SOBRE OS \\ PROFISSIONAIS MAIS VELHOS}

Os resultados da pesquisa apontaram que, de modo geral, os gestores possuem uma percepção relativamente positiva em relação aos profissionais mais velhos. Para eles, questões como comprometimento, fidelidade à empresa, pontualidade, capacidade de realizar diagnósticos precisos e equilíbrio emocional foram lembrados como pontos favoráveis associados aos colaboradores de mais idade.

Os gestores também avaliaram quais são os principais benefícios de se ter funcionários mais velhos compondo o ambiente de trabalho, e chegaram à conclusão de que eles estão ligados à experiência profissional, à diversidade de ideias e à capacidade de disseminar a cultura e as condutas esperadas pela organização.

Apesar de predominar uma percepção relativamente positiva sobre esses profissionais, alguns aspectos negativos também se fizeram presentes na avaliação dos gestores. A idade é associada à incapacidade de realizar trabalhos físicos pesados, dificuldade de adaptação às mudanças e às novas tecnologias, preferência por atividades que apresentam menos desafios, inflexibilidade e falta de disposição para receber treinamentos.

Além disso, os entrevistados identificaram barreiras quanto à integração dos colaboradores maduros com as equipes de trabalho. Esses obstáculos estão ligados à proximidade da aposentadoria, percepções de limitações físicas e mentais, dificuldade de se manterem atualizados segundo as necessidades do mercado, exigência de maiores salários e resistência para lidar com a liderança de profissionais mais jovens.

Apesar do reconhecimento das contribuições desses profissionais, será que as organizações estão atuando de forma a valorizá-los em seu espaço de trabalho?

\section{PRÁTICAS DE GESTÃO DA IDADE}

As práticas de gestão são iniciativas que combatem as barreiras impostas à idade e promovem a diversidade nas organizações, colaborando para criar um ambiente no qual os funcionários mais velhos são capazes de atingir o seu potencial. 


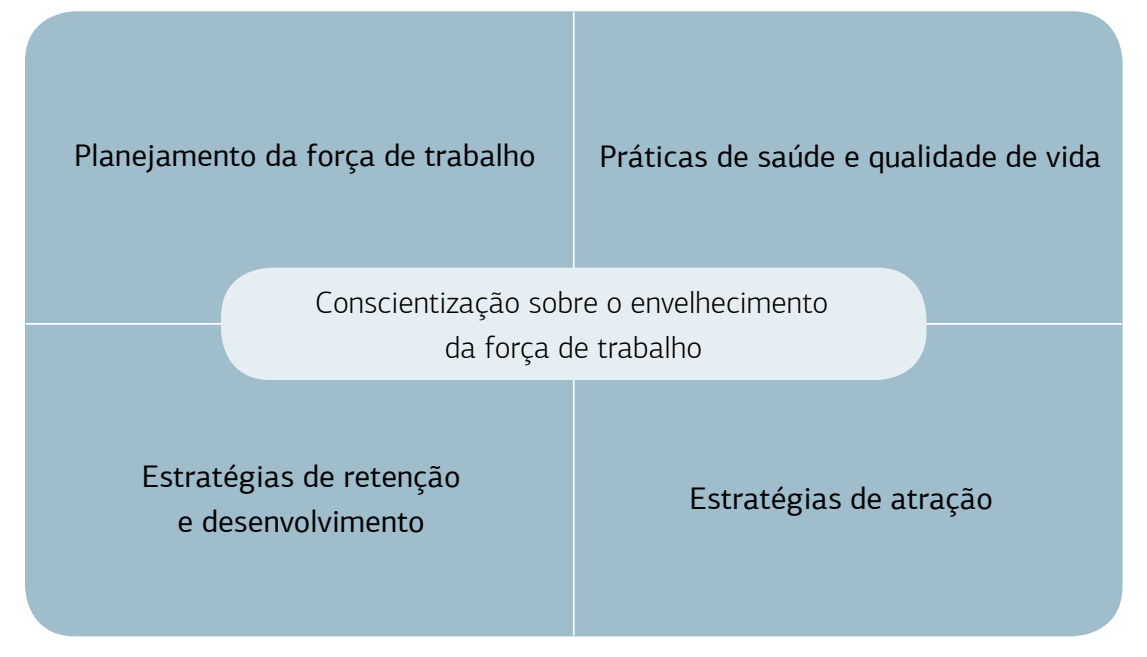

É IMPORTANTE

IMPLANTAR INICIATIVAS

QUE PROMOVAM

A DIVERSIDADE, COLABORANDO PARA

UM AMBIENTE ONDE FUNCIONÁRIOS COM MAIS IDADE SEJAM CAPAZES DE ATINGIR O SEU POTENCIAL

$\mathrm{Na}$ figura acima, o planejamento da força de trabalho refere-se à análise dos dados demográficos da empresa, considerando as projeções de aposentadoria e os índices de turnover. Dessa forma, é possível estimar as necessidades futuras de contratação da instituição.

As práticas de saúde e qualidade de vida estão ligadas à manutenção de uma equipe saudável e à reestruturação do local de trabalho a partir do que os colaboradores mais velhos precisam.

As estratégias de retenção e desenvolvimento estão relacionadas à flexibilidade de jornadas de trabalho, tipos de atividades, envolvimento em programas de transferência de conhecimento, treinamentos e trabalhos compartilhados entre diferentes gerações.

Finalmente, as estratégias de atração implicam na revisão de métodos de recrutamento para torná-los mais competitivos e adotar estratégias inovadoras.

As principais dimensões de boas práticas no ambiente corporativo podem ocorrer durante o processo de recrutamento, formação, desenvolvimento e promoção. Na pesquisa, foi possível constatar que as atividades apresentadas geralmente não são implementadas nas empresas onde pessoas com mais idade atuam.

Os resultados mostraram que práticas de saúde, que visam minimizar os efeitos do envelhecimento, não são adotadas, assim como não existem políticas de remuneração ou benefícios diferenciados aos mais velhos, nem a elaboração de treinamentos e campanhas especiais para a contratação desses candidatos. Além disso, as empresas não trabalham com planos de carreira especializados ou a preparação desse público para o desenvolvimento de uma atividade autônoma.

\section{INCOERÊNCIAS EM EVIDÊNCIA}

Embora na visão dos gestores os profissionais maduros possuam mais conhecimento útil para o dia a dia da empresa do que os jovens, práticas que tenham como foco a transferência dessas informações não são adotadas. Apesar disso, ainda assim os gestores determinaram que alguns dos principais benefícios de se ter funcionários mais velhos na empresa é a experiência técnica adquirida ao longo da carreira, a diversidade de pontos de vista e a capacidade dessas pessoas em disseminar a cultura e os comportamentos desejados pela organização.

Não obstante os gestores acreditem que os mais velhos apresentam atributos como produtividade, confiabilidade, comprometimento e pontualidade, verificou-se que, na maioria das vezes, as empresas não possuem uma postura proativa na contratação de profissionais maduros ou que estão próximos da idade de se aposentar. Ou seja, eles pouco consideram um funcionário com mais idade como alternativa de mão de obra, mesmo no contexto atual do país, em que a busca por qualificação está intensificada.

Além disso, embora a saúde seja um tópico de importância para que os colaboradores sejam capazes de realizar suas funções laborais, e apesar dos gestores acreditarem que uma das principais barreiras de se ter profissionais mais velhos no ambiente de trabalho seja a questão das limitações físicas e mentais, não são aplicadas práticas 


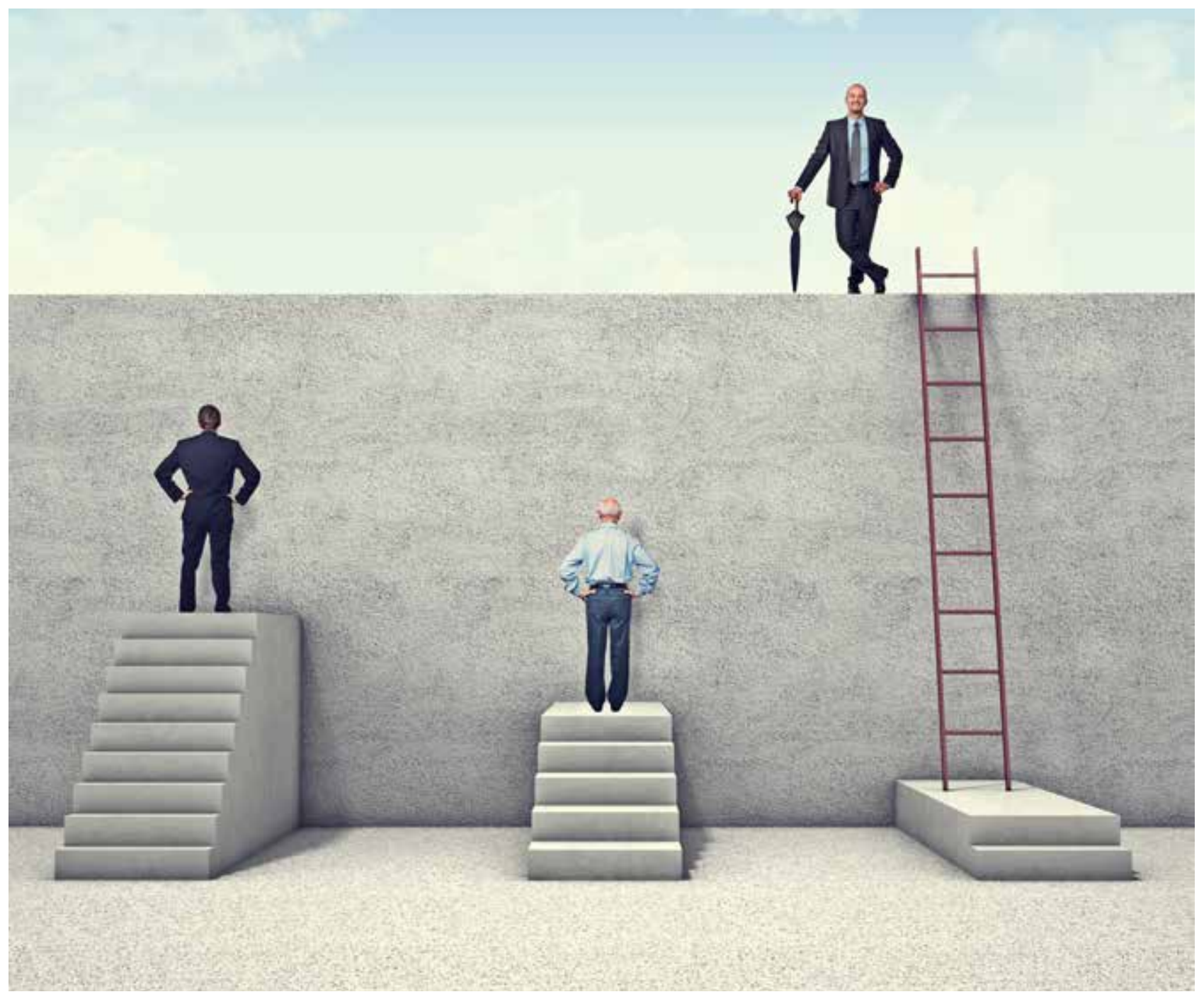

relacionadas à manutenção da saúde do funcionário e à prevenção de doenças.

Essas incoerências são preocupantes para o futuro das organizações, pois apesar dos dados demográficos apontarem para o envelhecimento acelerado da população brasileira e, consequentemente, da força produtiva a partir de 2040, as empresas mostram-se despreparadas para enfrentar esse cenário. Ademais, o ageism se fez presente a partir da evidência de práticas discriminatórias de emprego.

Uma das mudanças necessárias é a de caráter cultural. Os gestores devem ser educados e buscar conhecimento sobre os profissionais com mais idade, a fim de não alimentarem estereótipos negativos e inviabilizarem sua atuação. A pesquisa mostrou que esses estereótipos têm criado barreiras para a inclusão dessas pessoas no mercado de trabalho. Para que essa situação seja revertida, recomendamos as boas práticas de gestão da idade apresentadas na figura da página anterior.

Em síntese, se considerarmos que estamos em um país que envelhece rapidamente, é preciso rever preconceitos e revisar as políticas e práticas de gestão de pessoas para adequar as empresas a um futuro que já está batendo à porta.

VANESSA MARTINES CEPELLOS > Doutoranda da FGV-EAESP > vanessacepellos@hotmail.com MARIA JOSÉ TONELLI > Professora da FGV-EAESP > maria.jose.tonelli@fgv.br FRANCISCO ARANHA > Professor da FGV-EAESP > francisco.aranha@fgv.br

JOÃO LINS PEREIRA FILHO > Professor da FGV-EAESP e Sócio da PwC > joao.lins@br.pwc.com 